\title{
Recent Developments in the Endoscopic Treatment of Patients with Peptic Ulcer Bleeding
}

\author{
Jae-Young Jang \\ Department of Internal Medicine, Kyung Hee University School of Medicine, Seoul, Korea
}

Peptic ulcer bleeding is an internal medical emergency. Endoscopic hemostasis has been shown to improve the survival rate of patients with peptic ulcer bleeding. Although the established hemostatic modalities, including injection, thermal therapy, and mechanical therapy, are effective in controlling peptic ulcer bleeding, hemostasis can be difficult to achieve in some cases. As a result, recent, new endoscopic hemostatic modalities, including over-the-scope clips, topical hemostatic sprays, and endoscopic ultrasonography-guided angiotherapy, have been developed. Clin Endosc 2016;49:417-420

Key Words: Peptic ulcer hemorrhage; Hemostasis, endoscopic; Over-the-scope clips; Topical hemostatic sprays

\section{INTRODUCTION}

Upper gastrointestinal bleeding (UGIB) is a potentially lethal internal medical emergency. Its incidence rate is 40 to 150 cases per 100,000 populations. ${ }^{1,2}$ Approximately $80 \%$ to $90 \%$ of UGIB cases are associated with nonvariceal bleeding, predominantly peptic ulcer bleeding., ${ }^{3,4}$ Owing to the development of endoscopic management and increased use of proton pump inhibitors for the treatment of these patients, the incidence rate of UGIB has been decreasing; however, the incidence rate of peptic ulcer bleeding caused by aspirin and nonsteroidal anti-inflammatory drugs has been increasing. ${ }^{5,6}$ Despite the decrease in the incidence rate of UGIB and the advancement of therapeutic techniques, the mortality rate of patients with UGIB has remained unchanged at $10 \%$ to $14 \%$ for the past 30 years. ${ }^{5}$ This fact has been attributed to the increase in the aging population with other comorbid conditions and to pa-

Received: September 9, 2016 Revised: September 21, 2016

Accepted: September 22, 2016

Correspondence: Jae-Young Jang

Department of Internal Medicine, Kyung Hee University School of Medicine, 23 Kyungheedae-ro, Dongdaemun-gu, Seoul 02447, Korea

Tel: +82-2-958-8150, Fax: +82-2-958-8199, E-mail: jyjang@khu.ac.kr

(cc) This is an Open Access article distributed under the terms of the Creative Commons Attribution Non-Commercial License (http://creativecommons.org/ licenses/by-nc/3.0) which permits unrestricted non-commercial use, distribution, and reproduction in any medium, provided the original work is properly cited. tients not receiving endoscopic management in time, which could have increased their survival. The aim of this lecture is to provide information on the updated endoscopic treatment of bleeding peptic ulcer.

\section{GOALS OF ENDOSCOPIC MANAGEMENT}

The short-term goal for treating patients with UGIB is the prevention of rebleeding, and the long-term goal is to lower the associated mortality rate. In a meta-analysis, endoscopic management was a more effective treatment than pharmacological managements or placebo for lowering the rebleeding and mortality rates in patients with UGIB. ${ }^{7}$ Prognostic factors that are associated with higher mortality of patients with UGIB include old age, comorbid conditions, history of shock at the time of hospital visit, consistent bleeding, and rebleeding. ${ }^{8}$ Although endoscopic management cannot alleviate the effects of the aforementioned prognostic factors such as old age, comorbid conditions, and shock at the time of hospital visit, it may lower the mortality of patients with UGIB by preventing consistent bleeding and rebleeding.

\section{ENDOSCOPIC MANAGEMENT}

Patients with acute UGIB are recommended to undergo 
early endoscopic management within 24 hours of their hospital visit. ${ }^{9}$ Early endoscopic management has been reported to decrease the length of hospitalization, in comparison with delayed endoscopy, in high- and low-risk groups. ${ }^{10}$ Endoscopic management should be considered within 12 hours of hospital admission if unstable vital signs (e.g., tachycardia and hypotension), hematemesis, and active bleeding in the nasogastric tube are observed, or contraindication to the interruption of anticoagulation is present. ${ }^{11}$ Bleeding stigmata of peptic ulcers, which may be used to predict the risk of rebleeding, can be classified according to the Forrest (F) classification as follows: Ia (spurting hemorrhage), Ib (oozing hemorrhage), IIa (visible vessel), IIb (adherent clot), IIc (black or red spot), and III (clean ulcer base). ${ }^{12}$ Without endoscopic management, the risk of rebleeding is $100 \%$ for Ia, $30 \%$ to $40 \%$ for $\mathrm{Ib}, 50 \%$ for $\mathrm{II}$, $35 \%$ to $40 \%$ for IIb, $3 \%$ to $5 \%$ for IIc, and $0 \%$ to $1 \%$ for III. ${ }^{12}$ Therefore, endoscopic management is absolutely indicated for patients with high-risk stigmata (FI or FIIa). Patients with low-risk stigmata (FIIc or FIII) may resume oral intake within 24 hours without undergoing endoscopic management, be discharged early from the hospital, and be effectively treated in an outpatient setting. ${ }^{11}$

The efficacy of endoscopic management in the treatment of patients with ulcers with adherent clots is controversial. According to a study, $26 \%$ to $43 \%$ of adherent clots could be removed through vigorous irrigation and approximately $70 \%$ of visible vessels were observed on the ulcer base after clot removal. ${ }^{13}$ Therefore, endoscopic management is efficacious in only $50 \%$ to $60 \%$ of patients with FIIb. Moreover, the reported risk of rebleeding range from $0 \%-8 \%$ to $25 \%-35 \%$ in patients with clots that remain adherent after washing without endoscopic therapy, and whether endoscopic management is efficacious in patients with FIIb remains unclear. ${ }^{13}$ Therefore, endoscopic management must be performed only after clots have been removed from the ulcer base, when the ulcer base is actively bleeding, or when vessels are visible.

\section{ENDOSCOPIC HEMOSTASIS}

Endoscopic hemostasis can be divided into monotherapy and combined therapy. Monotherapy includes injection, thermal, mechanical modalities, and topical therapy.

\section{Injection therapy}

Injection therapy stops hemorrhage by inducing local tamponade resulting from a volume effect. Epinephrine, distilled water, cyanoacrylate, ethanolamine, thrombin, sodium tetradecyl sulfate, ethanol, and fibrin glue are used as injection therapy. Epinephrine injection (1:10,000 or 1:20,000 with nor- mal saline injected in 0.5 to $2 \mathrm{~mL}$ aliquots in and around the ulcer base) has shown hemostatic effects not only through induction of local tamponade but also through vasoconstriction and platelet aggregation. ${ }^{14}$ Although epinephrine injection is more effective than medical treatment for hemostasis, its therapeutic efficacy has been suboptimal compared with other endoscopic hemostatic modalities. Therefore, epinephrine injection alone is no longer recommended and should be used in combination with another method. Combining epinephrine injection with another hemostasis modality has shown decreased rates of rebleeding, surgery, and mortality compared with epinephrine injection alone. ${ }^{15}$ Sclerosing agents such as absolute ethanol, ethanolamine, and polidocanol induce hemostasis through direct injury of blood vessels and thrombosis. The volume of sclerosing agents must be controlled before injection to avoid possible necrosis and perforation. Another class of injectable agents is tissue adhesives, which includes thrombin, fibrin, and cyanoacrylate glues that plug bleeding sites. No single solution for endoscopic injection is superior to another for inducing hemostasis.

\section{Thermal therapy}

In thermal therapy, visible vessels are directly destroyed. Thermal therapy includes contact and noncontact modalities. In contact thermal therapy, heater probe, bipolar electrocautery probes, and hemostatic forceps are used; while in noncontact thermal therapy, argon plasma coagulation (APC) is used. In contact thermal therapy, a heater probe generates heat directly, and bipolar electrocautery probes induce hemostasis via indirect generation of heat by passage of an electrical current through the tissue. In contact thermal therapy, the tip of the instrument is placed on a visible vessel, which is then coagulated with heat or electrical current. The standard setting for hemostasis of peptic ulcer bleeding is 15 to $20 \mathrm{~W}$ for 8 to 10 seconds. ${ }^{12}$ Hemostatic forceps are used to stop hemorrhage in the same way that biopsy forceps are used. We compared the hemostatic effects of hemostatic forceps and APC in a randomized, prospective manner. ${ }^{16}$ The rebleeding rate was $6.6 \%$ within 7 days and $9.9 \%$ within 30 days in the hemostatic forceps group, and $4.0 \%$ within 7 days and $6.7 \%$ within 30 days in the APC group. No significant difference in bleeding rate was found between the two groups. This study concluded that hemostatic forceps are safer than and as effective as APC in the treatment of peptic ulcer bleeding. ${ }^{16}$

Noncontact thermal devices include APC tools. APC uses high-frequency, monopolar alternating current conducted to the target tissue through a stream of ionized gas, resulting in coagulation of superficial tissue. ${ }^{17}$ Hemostasis is considered successful once bleeding is stopped and black carbide crusts form. An advantage of this technique is that it allows for eas- 
ier access to lesions that are normally difficult to approach. In addition, as the tissue surface loses its electrical conductivity, the argon plasma stream shifts to adjacent nondesiccated tissue, which again limits the depth of tissue injury. The electrocoagulative effect may carry a lower risk of intestinal perforation. Therefore, APC produces effective hemostatic results in superficial vascular lesions such as angiodysplasia and gastric antral vascular ectasia. No single application of endoscopic thermal coagulation is superior to another.

\section{Mechanical therapy}

In endoscopic mechanical therapies, clips (through-thescope clips and over-the-scope clips [OTSCs]), band ligation devices, and detachable loop-ligating devices may be used. A clip induces hemostasis by mechanical compression that passes through the ulcer base. Once a clip is fixed onto the base, it sloughs off within days to weeks. ${ }^{18}$ The through-the-scope clip is the most commonly used type. Many kinds of hemoclip devices have been developed, with variations in opening diameter, ease of rotation, and reopening. The major limitation of hemoclips is that they may be difficult to use in hard-toaccess areas such as the lesser curvature of the gastric body, posterior duodenum, or cardia. Moreover, if the ulcer base has hardened as a result of fibrosis, a clip may not be able to pierce through the ulcer base and touch vessels instead, which leads to bleeding. In addition, misplaced clips may become a hindrance during the next endoscopic therapy. Despite these shortcomings, clips are more effective than injection monotherapy. ${ }^{11,13}$

Endoscopic band ligation is typically used to achieve hemostasis in patients with esophageal variceal bleeding, Dieulafoy's lesion, Mallory-Weiss syndrome, and bleeding ulcers of small size. $^{19}$ An OTSC device consists of an applicator cap, nitinol clip, and handwheel..$^{20}$ The applicator cap, with the mounted nitinol clip, is affixed to the tip of the endoscope in a manner similar to that in a variceal band ligation device. After placing the endoscope tip near the lesion, the tissue is suck into the applicator cap and the clip is ejected by stretching the wire with the handwheel to stop hemorrhage. Clips come in two different shapes of teeth, rounded and pointed. According to a recent study, the OTSC attained $100 \%$ hemostasis, and the rebleeding prevention rate was $80 \%$ in patients with UGIB. ${ }^{21}$ The disadvantages of the OTSC are that it requires the scope to be withdrawn to load the device, the OTSC cap may make traversing the cricopharyngeus or luminal stenoses difficult, accessing the lesions in the posterior-inferior duodenal wall or proximal lesser curvature of the stomach is challenging, and its cost is high. To our knowledge, no prospective studies have been conducted to compare the hemostatic effects of OTSCs and through-the-scope clips, and the role of OTSCs in the treatment of patients with UGIB is still unclear. Today, OTSC is used in rescue hemostatic therapy when conventional endoscopic treatment modalities fail and in closure of iatrogenic full-thickness perforations of the gastrointestinal tract.

\section{Topical therapy}

Topical hemostatic spray has shown promising results in the treatment of patients with UGIB. However, these results cannot be completely trusted because of the small sample size and no studies have compared topical hemostatic spray with other hemostatic therapies. ${ }^{22}$ The advantages of using a hemostatic spray include the following: (1) it is easy to use and simply sprayed; (2) the lesion does not have to be precisely targeted; and (3) it allows for easier access to sites that are normally hard to access. Three types of topical hemostatic sprays have been developed as follows: TC-325, (Hemospray; Cook Medical Inc., Winston-Salem, NC, USA), EndoClot (EndoClot Plus Inc., Santa Clara, CA, USA), and Ankaferd Blood Stopper (Ankaferd Health Products Ltd., Istanbul, Turkey). TC-325 is a proprietary, inorganic, absorbent powder that activates coagulation factors near the hemorrhage site and forms coagulum to produce hemostatic effects. Coagulum is naturally peeled off and removed within 3 days of application. In a recent study of 20 patients with UGIB, researchers investigated the safety and efficacy of hemospray. No side effects, death, or complications from bleeding were observed during the 30-day follow-up for acute bleeding at 95\%. In a group of patients at high risk of rebleeding (FIa and Ib), hemostasis was also performed at $90 \%$ and the risk of rebleeding within 7 days was $22 \%{ }^{23}$ EndoClot is a starch-derived compound that induces hemostasis by activating a coagulating process where water is absorbed into the hemorrhage site from serum, and platelets, erythrocytes, and coagulated proteins agglutinate together. Ankaferd Blood Stopper promotes the formation of a protein mesh, which becomes a foothold for hemaglutination without the influence of platelet coagulation factors. Topical agents are effective for inducing hemostasis of oozing-type lesions. The hemostatic effects of topical agents in active arterial bleeding have not been verified because hemostatic agents cannot effectively attach to the hemorrhage site but tend to get washed away by the continuous bleeding. Moreover, topical agents have been reported to be lacking in the case of FIIa. In a systematic review of the current limited data, hemospray is considered a bridge therapy because it is safe and effective, but has temporary effects. ${ }^{22}$ A more-randomized prospective research is warranted to verify the effectiveness of hemostatic powders in the treatment of patients with peptic ulcer bleeding.

\section{Endoscopic ultrasonography-guided angiotherapy}

The effectiveness of endoscopic ultrasonography (EUS)-guided 
angiotherapy has been investigated by a number of small-scale studies. ${ }^{24}$ EUS-guided angiotherapy was effective in patients with lesions that had not been effectively treated with typical endoscopic therapies. EUS-guided angiotherapy therapy involves identification of vessels around the hemorrhage site by using EUS before performing hemostasis. Recently, EUS-guided cyanoacrylate injection was reported to be a relatively safe method and to have prevented rebleeding in the long term in patients with duodenal ulcers.

\section{CONCLUSIONS}

Injection of sclerosants, thermal therapy, and mechanical therapy as monotherapy or in combination with epinephrine injection are currently the most recommended and effective methods of achieving hemostasis. Topical therapy and OTSCs have been developed to attain greater hemostatic effects more easily; however, more large-scale studies are needed to confirm their usefulness, efficacy, and safety.

\section{Conflicts of Interest}

The author has no financial conflicts of interest.

\section{REFERENCES}

1. van Leerdam ME. Epidemiology of acute upper gastrointestinal bleeding. Best Pract Res Clin Gastroenterol 2008;22:209-224.

2. Hearnshaw SA, Logan RF, Lowe D, Travis SP, Murphy MF, Palmer KR. Acute upper gastrointestinal bleeding in the UK: patient characteristics, diagnoses and outcomes in the 2007 UK audit. Gut 2011;60:1327-1335.

3. Rockall TA, Logan RF, Devlin HB, Northfield TC. Incidence of and mortality from acute upper gastrointestinal haemorrhage in the United Kingdom. Steering Committee and members of the National Audit of Acute Upper Gastrointestinal Haemorrhage. BMJ 1995;311:222-226.

4. Barkun A, Sabbah S, Enns R, et al. The Canadian Registry on Nonvariceal Upper Gastrointestinal Bleeding and Endoscopy (RUGBE): endoscopic hemostasis and proton pump inhibition are associated with improved outcomes in a real-life setting. Am J Gastroenterol 2004;99:12381246.

5. van Leerdam ME, Vreeburg EM, Rauws EA, et al. Acute upper GI bleeding: did anything change? Time trend analysis of incidence and outcome of acute upper GI bleeding between 1993/1994 and 2000. Am J Gastroenterol 2003;98:1494-1499.

6. Lanas A, García-Rodríguez LA, Polo-Tomás M, et al. Time trends and impact of upper and lower gastrointestinal bleeding and perforation in clinical practice. Am J Gastroenterol 2009;104:1633-1641.
7. Cook DJ, Guyatt GH, Salena BJ, Laine LA. Endoscopic therapy for acute nonvariceal upper gastrointestinal hemorrhage: a meta-analysis. Gastroenterology 1992;102:139-148.

8. Barkun A, Bardou M, Marshall JK; Nonvariceal Upper GI Bleeding Consensus Conference Group. Consensus recommendations for managing patients with nonvariceal upper gastrointestinal bleeding. Ann Intern Med 2003;139:843-857.

9. Kanwal F, Barkun A, Gralnek IM, et al. Measuring quality of care in patients with nonvariceal upper gastrointestinal hemorrhage: development of an explicit quality indicator set. Am J Gastroenterol 2010;105:17101718.

10. Lin HJ, Wang K, Perng CL, et al. Early or delayed endoscopy for patients with peptic ulcer bleeding. A prospective randomized study. J Clin Gastroenterol 1996;22:267-271.

11. Gralnek IM, Dumonceau JM, Kuipers EJ, et al. Diagnosis and management of nonvariceal upper gastrointestinal hemorrhage: European Society of Gastrointestinal Endoscopy (ESGE) Guideline. Endoscopy 2015;47:a1-a46.

12. Forrest JA, Finlayson ND, Shearman DJ. Endoscopy in gastrointestinal bleeding. Lancet 1974;2:394-397.

13. Barkun AN, Bardou M, Kuipers EJ, et al. International consensus recommendations on the management of patients with nonvariceal upper gastrointestinal bleeding. Ann Intern Med 2010;152:101-113.

14. Barkun AN, Martel M, Toubouti Y, Rahme E, Bardou M. Endoscopic hemostasis in peptic ulcer bleeding for patients with high-risk lesions: a series of meta-analyses. Gastrointest Endosc 2009;69:786-799.

15. Vergara $M$, Calvet $X$, Gisbert JP. Epinephrine injection versus epinephrine injection and a second endoscopic method in high risk bleeding ulcers. Cochrane Database Syst Rev 2007;(2):CD005584.

16. Kim JW, Jang JY, Lee CK, Shim JJ, Chang YW. Comparison of hemostatic forceps with soft coagulation versus argon plasma coagulation for bleeding peptic ulcer: a randomized trial. Endoscopy 2015;47:680-687.

17. Ginsberg GG, Barkun AN, Bosco JJ, et al. The argon plasma coagulator: February 2002. Gastrointest Endosc 2002;55:807-810.

18. Raju GS, Gajula L. Endoclips for GI endoscopy. Gastrointest Endosc 2004;59:267-279.

19. Brock AS, Rockey DC. Mechanical hemostasis techniques in nonvariceal upper gastrointestinal bleeding. Gastrointest Endosc Clin N Am 2015;25:523-533

20. Kirschniak A, Kratt T, Stüker D, Braun A, Schurr MO, Königsrainer A. A new endoscopic over-the-scope clip system for treatment of lesions and bleeding in the GI tract: first clinical experiences. Gastrointest Endosc 2007;66:162-167.

21. Chan SM, Chiu PW, Teoh AY, Lau JY. Use of the over-the-scope clip for treatment of refractory upper gastrointestinal bleeding: a case series. Endoscopy 2014;46:428-431.

22. Barkun AN, Moosavi S, Martel M. Topical hemostatic agents: a systematic review with particular emphasis on endoscopic application in GI bleeding. Gastrointest Endosc 2013;77:692-700.

23. Sung JJ, Luo D, Wu JC, et al. Early clinical experience of the safety and effectiveness of Hemospray in achieving hemostasis in patients with acute peptic ulcer bleeding. Endoscopy 2011;43:291-295.

24. Fujii-Lau LL, Wong Kee Song LM, Levy MJ. New technologies and approaches to endoscopic control of gastrointestinal bleeding. Gastrointest Endosc Clin N Am 2015;25:553-567. 